\title{
Pseudomonas psychrotolerans sp. nov.
}

Correspondence Hans-Jürgen Busse hans-juergen.busse@ vu-wien.ac.at

\section{Elke Hauser, ${ }^{1}$ Peter Kämpfer ${ }^{2}$ and Hans-Jürgen Busse ${ }^{1,3}$}

\author{
${ }^{1}$ Institut für Bakteriologie, Mykologie und Hygiene, Veterinärmedizinische Universität, A-1210 \\ Vienna, Austria \\ ${ }^{2}$ Institut für Angewandte Mikrobiologie, Justus-Liebig-Universität Giessen, D-35392 Giessen, \\ Germany \\ ${ }^{3}$ Institut für Mikrobiologie und Genetik, Universität Wien, A-1030 Vienna, Austria
}

Three yellow-pigmented, Gram-negative, rod-shaped, non-spore-forming bacterial strains, $\mathrm{C} 6^{\top}$, C37 and C39, were isolated in the Medical Clinic for Small Animals and Ungulates at the University for Veterinary Medicine in Vienna, Austria. On the basis of 16S rRNA gene sequence similarity, strain $\mathrm{C}_{3} 6^{\top}$ was shown to belong to the genus Pseudomonas; Pseudomonas oleovorans DSM $1045^{\top}$ was the nearest relative ( $99.5 \%$ sequence similarity). Other Pseudomonas species shared $<97 \%$ sequence similarity with strain $\mathrm{C} 6^{\top}$. The presence of Q-9 as the major ubiquinone, the predominance of putrescine and spermidine in its polyamine patterns and its fatty acid profile [i.e. the predominance of $\mathrm{C}_{16: 0}$, summed feature $3\left(\mathrm{C}_{16: 1} \omega 7 \mathrm{c}\right.$ and/or 2-OH $\mathrm{C}_{15: 0}$ iso), $\mathrm{C}_{18: 1} \omega 7 \mathrm{c}$ and the presence of $3-\mathrm{OH} \mathrm{C}_{10: 0}, 3-\mathrm{OH} \mathrm{C} \mathrm{C}_{12: 0}$ and 2-OH $\mathrm{C}_{12: 0}$ ] were in agreement with identification of this strain as a member of the genus Pseudomonas. Physiological and biochemical characteristics and the results of genomic fingerprinting clearly differentiated strain C36 ${ }^{\top}$ from its phylogenetic relative $P$. oleovorans DSM $1045^{\top}$. Results from DNA-DNA hybridization showed that strain $\mathrm{C} 36^{\top}$ represents a species that is distinct from $P$. oleovorans DSM $1045^{\top}$. These data demonstrate that strain $\mathrm{C} 36^{\top}$ represents a novel species of the genus Pseudomonas, for which the name Pseudomonas psychrotolerans sp. nov. is proposed. The type strain is $\mathrm{C} 36^{\top}$ (=LMG $21977^{\top}=\mathrm{DSM} 15758^{\top}$ ). Additionally, physiological, biochemical, chemotaxonomic and genomic fingerprints indicate that $P$. oleovorans ATCC 29347 may not be a member of the species $P$. oleovorans sensu stricto.
During hygiene investigations at the Medical Clinic for Small Animals and Ungulates at the University for Veterinary Medicine in Vienna, Austria, numerous microorganisms were isolated. To identify significant groups, isolates that showed obvious similarities in colony morphology and pigmentation were compared by analysis of their protein patterns using SDS-PAGE (Altenburger et al., 1996). Protein similarity groups that consisted of at least three strains were characterized in more detail. Based on their preliminary classification, selected representatives of these protein similarity groups were identified as members of the yeast genus Rhodotorula, the bacterial

Published online ahead of print on 4 June 2004 as DOI 10.1099/ ijs.0.03024-0.

Abbreviation: ERIC-PCR, enterobacterial repetitive intergenic consensus sequence-based PCR.

The GenBank/EMBL/DDBJ accession number for the 16S rRNA gene sequence of Pseudomonas psychrotolerans $\mathrm{C} 6^{\top}$ is AJ575816.

A table giving fatty acid contents and figures showing two-dimensional TLC of polar lipids and SDS-PAGE analysis of strains C36 ${ }^{\top}, \mathrm{C} 37$ and C39 and related strains are available as supplementary material in IJSEM Online. genera Acinetobacter, Staphylococcus, Bacillus, Sphingomonas and Pseudomonas, and coliforms.

Taxonomic characterization of three yellow-pigmented strains $\left(\mathrm{C} 36^{\mathrm{T}}, \mathrm{C} 37\right.$ and $\left.\mathrm{C} 39\right)$, of which the representative strain, $\mathrm{C} 36^{\mathrm{T}}$, was preliminarily identified as a member of the genus Pseudomonas, is reported.

Strains $\mathrm{C} 36^{\mathrm{T}}$ and C37 were isolated from water under a dog's cage and strain C39 was isolated from a strip of metal under the treatment table after cultivation on PYE agar ( $\mathrm{pH} 7 \cdot 2)$, which contained $\left(1^{-1}\right): 3 \cdot 0 \mathrm{~g}$ peptone from casein, $3.0 \mathrm{~g}$ yeast extract and $15.0 \mathrm{~g}$ agar. The isolates were subcultivated on PYE agar at $28^{\circ} \mathrm{C}$ for $48 \mathrm{~h}$. Pseudomonas oleovorans DSM $1045^{\mathrm{T}}$ and P. oleovorans ATCC 29347 were kindly provided by G. Schroll, Institute of Microbiology and Genetics, University of Vienna, Vienna, Austria.

The 16S rRNA gene was amplified and analysed as described previously (Zlamala et al., 2002). The 16S rRNA gene sequence of strain $\mathrm{C} 36^{\mathrm{T}}$ was a continuous stretch of $1456 \mathrm{nt}$. Sequence comparisons (ungapped) by using FASTA3 (Pearson \& Lipman, 1988) indicated that the closest 
relative of strain $\mathrm{C} 36^{\mathrm{T}}$ is P. oleovorans DSM $1045^{\mathrm{T}}(99 \cdot 5 \%$ sequence similarity). Moderate sequence similarities (96.0$96 \cdot 8 \%)$ were found to other selected species of the genus Pseudomonas. Phylogenetic calculations supported the high degree of relatedness between strain $\mathrm{C} 36^{\mathrm{T}}$ and P. oleovorans DSM $1045^{\mathrm{T}}$ (Fig. 1).

Physiological characterization was done as described previously (Kämpfer et al., 1991). Growth at different temperatures was examined on PYE agar, $\mathrm{NaCl}$ tolerance was tested on PYE agar supplemented with $\mathrm{NaCl}$ and production of fluorescent pigment was assayed on King's B medium. Growth on TSA, R2A and MacConkey agar was also tested. Growth under microaerobic $\left(95 \% \mathrm{~N}_{2}, 5 \% \mathrm{CO}_{2}\right.$, with $1 \cdot 5-2 \cdot 0 \%$ remaining $\mathrm{O}_{2}$ ) and anaerobic $\left(9-13 \% \mathrm{CO}_{2}\right.$, $<1 \% \mathrm{O}_{2}$ within $30 \mathrm{~min}$ ) conditions was examined on PYE agar. Strains $\mathrm{C}^{2} 6^{\mathrm{T}}, \mathrm{C} 37$ and $\mathrm{C} 39$ showed a high degree of similarity in their physiological characteristics. Out of 102 tests, the three strains reacted identically in 93 tests, which corresponds to $91 \%$ similarity. In contrast, the similarities in reaction profiles between these isolates and their nearest phylogenetic relative, $P$. oleovorans DSM $1045^{\mathrm{T}}$, and also P. oleovorans ATCC 29347 , as well as the similarity between these two strains of $P$. oleovorans, were

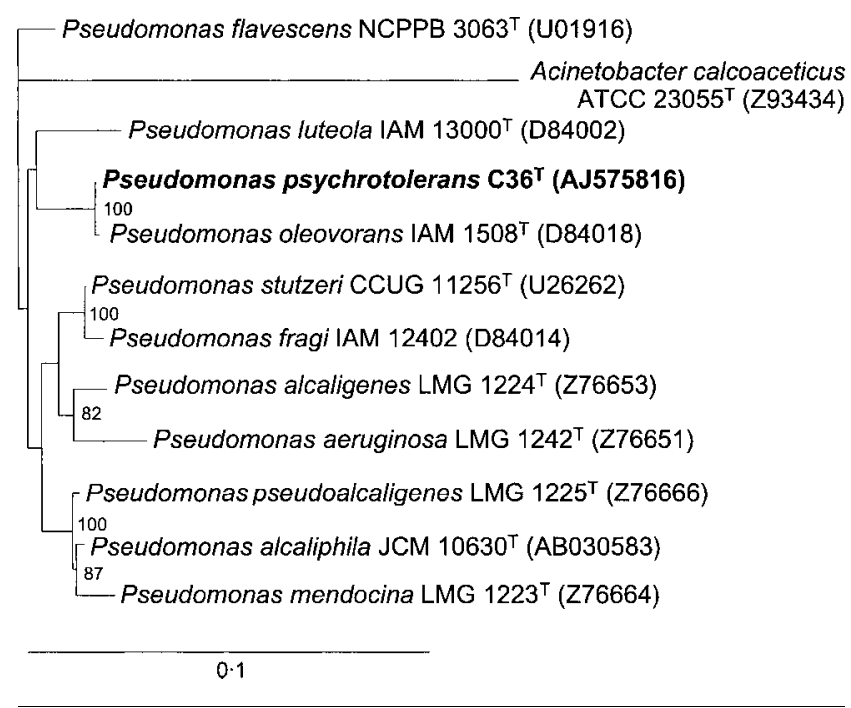

Fig. 1. Phylogenetic tree indicating the estimated relationship between strain $\mathrm{C} 6^{\top}$ (GenBank accession no. AJ575816) and species of the genus Pseudomonas that shared highest $16 \mathrm{~S}$ rRNA gene sequence similarities. Sequences of reference species were obtained from GenBank/EMBL and Acinetobacter calcoaceticus ATCC $23055^{\top}$ was selected as the outgroup. Sequences were aligned by using CLUSTAL X (Thompson et al., 1997) and edited manually to remove ambiguous nucleotides and gaps. The tree was constructed based on a continuous stretch of $1389 \mathrm{nt}$ by using the neighbour-joining method (Saitou \& Nei, 1987) included in the PHYLIP package (Felsenstein, 1995). The tree was visualized by using TREEVIEW (Page, 1996). Bar, 10\% sequence dissimilarity.
$<80 \%$ (Table 1). The results are listed in Table 1 and in the species description.

Chemotaxonomic analyses were done as described previously: respiratory quinones and polar lipids (Tindall, 1990; Altenburger et al., 1996); polyamines (Busse \& Auling, 1988; Busse et al., 1997); and fatty acids (Kämpfer et al., 1997). The results are given in the species description.

The quinone system and polyamine pattern of strains $\mathrm{C}^{2} 6^{\mathrm{T}}$ and C39 were in excellent agreement with the characteristics of the genus Pseudomonas sensu stricto (Oyaizu \& Komagata, 1983; Busse \& Auling, 1988; Auling et al., 1991). The fatty acid profile of strains $\mathrm{C} 36^{\mathrm{T}}, \mathrm{C} 37$ and C39 showed the same major characteristics as those of $P$. oleovorans DSM $1045^{\mathrm{T}}$ and P. oleovorans ATCC 29347 (see Supplementary Table, available in IJSEM Online). However, our isolates differed from P. oleovorans strains DSM $1045^{\mathrm{T}}$ and ATCC 29347 in terms of quantitative differences of certain acids, such as summed feature $3\left(\mathrm{C}_{16: 1} \omega 7 \mathrm{c}\right.$ and/or $2-\mathrm{OH}$ $\mathrm{C}_{15: 0}$ iso), $\mathrm{C}_{16: 0}$ and $\mathrm{C}_{18: 1} \omega 7 \mathrm{c}$. Differentiation between P. oleovorans DSM $1045^{\mathrm{T}}$ and P. oleovorans ATCC 29347 was possible by examining differences in the relative amounts of 2-OH C $12: 0$, summed feature $3, \mathrm{C}_{16: 0}$ and $\mathrm{C}_{18: 1} \omega 7 c$ (see Supplementary Table in IJSEM Online).

Polar lipid profiles are relatively conserved characteristics with varying specificity, depending on the taxon. Sometimes, a polar lipid profile contains a genus- or familyspecific characteristic, such as sphingoglycolipid in species of the family Sphingomonadaceae, but the complete profile is specific for a species or very closely related species (Busse et al., 1999). The polar lipid profiles of strains $\mathrm{C} 36^{\mathrm{T}}$ (see Supplementary Fig. A in IJSEM Online) and C39 (results not shown) were identical. Their polar lipid profiles shared a high degree of similarity with that of $P$. oleovorans DSM $1045^{\mathrm{T}}$. However, strains $\mathrm{C} 36^{\mathrm{T}}$ and C39 could be distinguished clearly from $P$. oleovorans DSM $1045^{\mathrm{T}}$ by the presence of two yellow pigment spots in their chromatograms. Differentiation between P. oleovorans DSM $1045^{\mathrm{T}}$ and $P$. oleovorans ATCC 29347 was possible by the absence of phosphatidylcholine in P. oleovorans ATCC 29347 (see Supplementary Fig. A in IJSEM Online).

SDS-PAGE was performed with strains $\mathrm{C} 36^{\mathrm{T}}$, C37, C39, P. oleovorans DSM $1045^{\mathrm{T}}$ and P. oleovorans ATCC 29347 as described previously (Altenburger et al., 1996). Comparisons of the protein patterns demonstrated that strains C36 ${ }^{\mathrm{T}}, \mathrm{C} 37$ and $\mathrm{C} 39$ are almost indistinguishable and thus they can be considered to be members of a single species. No significant similarities were detected between the protein patterns of these three isolates and those of $P$. oleovorans DSM $1045^{\mathrm{T}}$ and P. oleovorans ATCC 29347 . However, the protein patterns could be used to distinguish between P. oleovorans strains DSM $1045^{\mathrm{T}}$ and ATCC 29347 (see Supplementary Fig. B in IJSEM Online).

Genomic fingerprints of strains $\mathrm{C} 6^{\mathrm{T}}, \mathrm{C} 37$ and $\mathrm{C} 39$ obtained after enterobacterial repetitive intergenic 
Table 1. Physiological characteristics of $P$. psychrotolerans, $P$. oleovorans DSM $1045^{\top}$ and $P$. oleovorans ATCC 29347

Species/strains: 1, P. psychrotolerans $(n=3)$; 2, P. oleovorans DSM $1045^{\mathrm{T}}$; 3, P. oleovorans ATCC 29347. + , Positive; $(+)$ weakly positive; -, negative; V, variable. Abbreviations: pNP, para-nitrophenyl; pNA, para-nitroanilide. Test results were read after $72 \mathrm{~h}$ incubation at $30^{\circ} \mathrm{C}$. All strains were able to grow under microaerobic, but not anaerobic, conditions. They all grew on R2A, TSA, MacConkey agar, PYE agar supplemented with 1 or $5 \% \mathrm{NaCl}$ and at temperatures of 15,28 and $37^{\circ} \mathrm{C}$. None of the strains was able to grow on PYE agar supplemented with $7 \cdot 5$ or $10 \% \mathrm{NaCl}$. All strains were negative for acid production from lactose, sucrose, dulcitol, salicin, adonitol, raffinose, cellobiose, methyl D-glucoside and erythritol. All strains were negative for hydrolysis of aesculin, pNP- $\beta$-D-galactopyranoside, pNP- $\beta$-D-glucuronide, pNP- $\alpha$-D-glucopyranoside, pNP- $\beta$-D-glucopyranoside, pNP- $\beta$-D-xylopyranoside, pNP-phosphorylcholine and L-glutamate- $\gamma$-3-carboxy-pNA. All strains were positive for hydrolysis of L-alanine-pNA. All strains were negative for assimilation of $N$-acetyl-D-galactosamine, $N$-acetyl-Dglucosamine, $p$-arbutin, D-cellobiose, $\alpha$-D-melibiose, sucrose, salicin, adonitol, maltitol, adipate, azelate, L-tryptophan, 3-hydroxybenzoate and suberate. All strains were positive for assimilation of D-glucose, putrescine, fumarate, glutarate, DL-3-hydroxybutyrate, 4-aminobutyrate, DL-lactate, L-malate, oxoglutarate, pyruvate, 4-hydroxybenzoate, L-alanine, L-proline and L-serine.

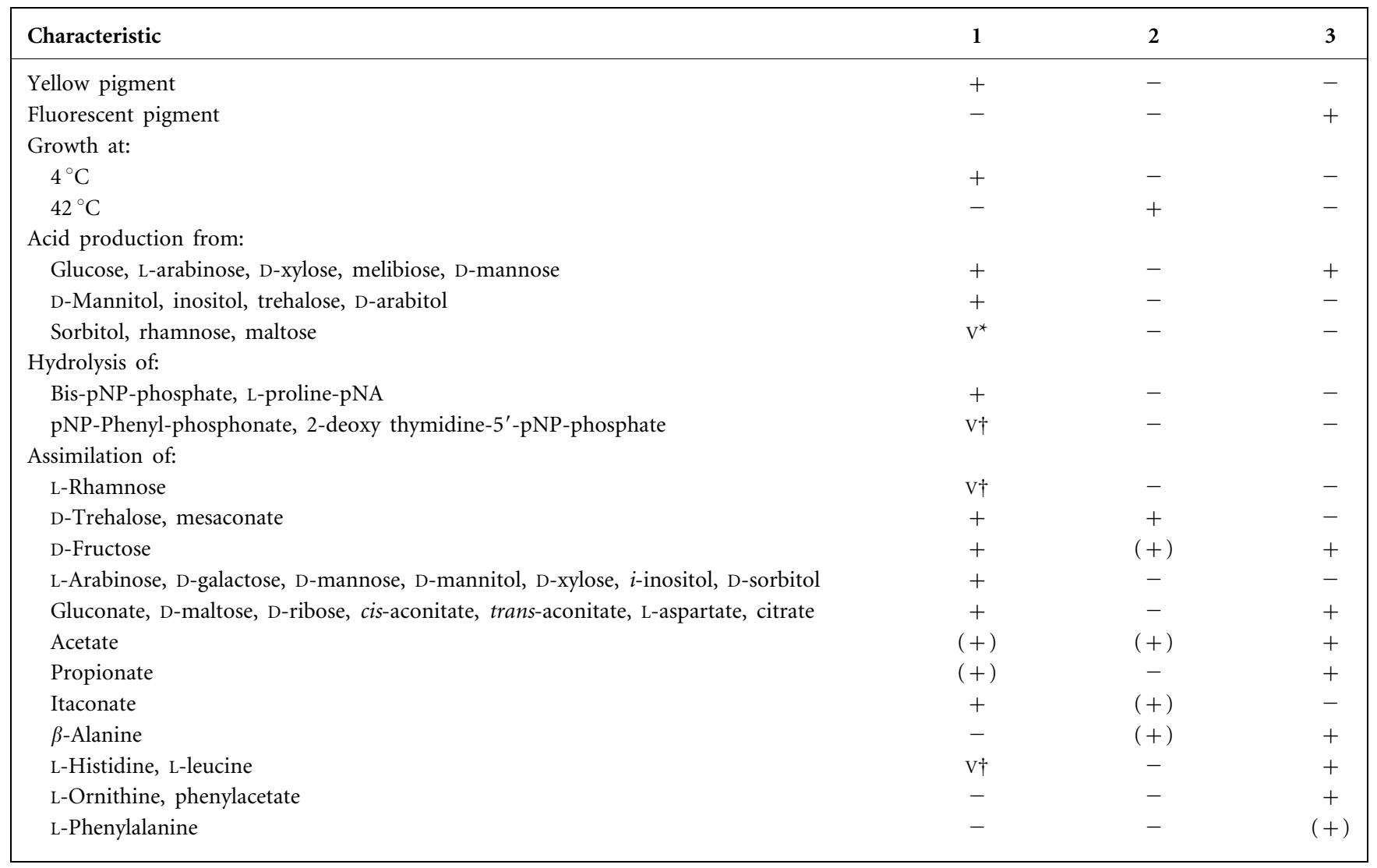

${ }^{*}$ The type strain reacts negatively.

$\dagger$ The type strain reacts positively.

consensus sequence-based PCR (ERIC-PCR) (Wieser \& Busse, 2000) revealed that they shared at least two of the three major bands, indicating that the three strains are highly related. No similarities were observed between the fingerprints of our isolates and those of P. oleovorans DSM $1045^{\mathrm{T}}$ and P. oleovorans ATCC 29347 (Fig. 2). Thus, the ERIC-PCR-generated fingerprints are in agreement with our other findings and indicate that our three isolates are members of a novel, so far unrecognized, single species. DNA-DNA hybridizations between strain $\mathrm{C} 36^{\mathrm{T}}$ and $P$. oleovorans DSM $1045^{\mathrm{T}}$, which were performed according to Ziemke et al. (1998) and Kämpfer et al. (2003), showed 6 and $8 \%$ (reciprocal values) relatedness. These values demonstrate unambiguously that the two strains belong to different species.

Results from analysis of the 16S rRNA gene, polyamine patterns, the quinone system, polar lipids and fatty acids indicate that strain $\mathrm{C}^{2} 6^{\mathrm{T}}$ is a member of the genus Pseudomonas and that it is related closely to P. oleovorans DSM $1045^{\mathrm{T}}$.

Strains $\mathrm{C} 36^{\mathrm{T}}, \mathrm{C} 37$ and C39 are strikingly homogeneous in terms of their protein patterns, ERIC-PCR-generated genomic fingerprints and physiological traits and thus they can be considered to be members of a single species. 


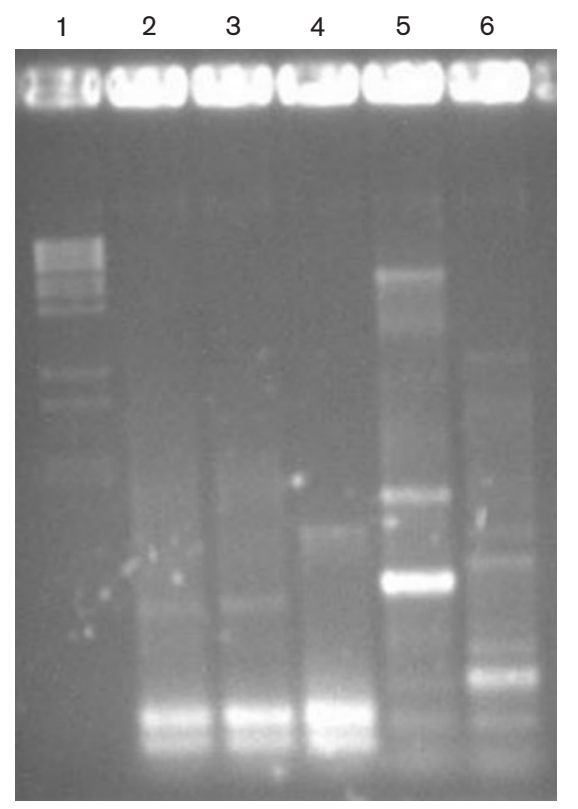

Fig. 2. ERIC-PCR-generated genomic fingerprinting. Lanes: 1 , $\lambda$ BstEll digest; 2, С39; 3, С37; 4, С36 ${ }^{\top} ; 5$, P. oleovorans DSM $1045^{\top} ; 6, P$. oleovorans ATCC 29347.

They can be distinguished from the two strains of $P$. oleovorans by genomic fingerprints, protein patterns, fatty acid composition, polar lipid profiles and numerous physiological characteristics. Data from DNA-DNA hybridization between strain $\mathrm{C} 36^{\mathrm{T}}$ and P. oleovorans DSM $1045^{\mathrm{T}}$ demonstrate that they belong to different species. Based on these results, it is concluded that our isolates represent a novel species of the genus Pseudomonas, for which the name Pseudomonas psychrotolerans sp. nov. is proposed. The species description is given below.

Based on clearly differing protein patterns after SDSPAGE, ERIC-PCR-generated fingerprints and significant differences in physiological characteristics, as well as in fatty acid and polar lipid profiles, it is assumed that $P$. oleovorans DSM $1045^{\mathrm{T}}$ and P. oleovorans ATCC 29347 do not belong to a single species. Our assumption is supported by comparison of the $16 \mathrm{~S}$ rRNA gene sequence of P. oleovorans ATCC 29347 (GenBank accession no. AJ249825), which has been published recently (van Beilen et al., 2001). Similarity values demonstrate that it is related closely to the 16S rRNA gene sequence of Pseudomonas plecoglossicida FPC $951^{\mathrm{T}}$ (99.9\% sequence similarity) and to sequences of other members of the Pseudomonas putida lineage (Moore et al., 1996), including Pseudomonas monteilii CIP $104883^{\mathrm{T}}(99 \cdot 7 \%)$, Pseudomonas mosselii CIP $105259^{\mathrm{T}}(99 \cdot 4 \%)$ and P. putida DSM $291^{\mathrm{T}}(98 \cdot 9 \%)$. In contrast, P. oleovorans ATCC 29347 shares only $97 \cdot 5 \% 16 \mathrm{~S}$ rRNA gene sequence similarity with $P$. oleovorans DSM $1045^{\mathrm{T}}$. Thus, it is suggested that $P$. oleovorans ATCC 29347 might be a strain of $P$. plecoglossicida, although DNA-DNA hybridization studies or comparison of genomic fingerprints will be necessary to clarify its taxonomic status.

\section{Description of Pseudomonas psychrotolerans sp. nov.}

Pseudomonas psychrotolerans (psy.chro.to'ler.ans. Gr. adj. psychros cold; L. pres. part. tolerans tolerating; N.L. part. adj. psychrotolerans cold-tolerating).

Cells are Gram-negative, non-spore-forming rods with slightly exaggerated poles, $0.5-0 \cdot 7 \times 1 \cdot 5-1 \cdot 8 \mu \mathrm{m}$. Cells generally occur singly, but sometimes in pairs. Oxidasenegative and catalase-positive. Growth occurs under aerobic and microaerobic, but not anaerobic, conditions. Motility is observed by light microscopy. Good growth occurs on PYE agar, TSA, R2A and MacConkey agar, on PYE agar supplemented with $1-5 \%(\mathrm{w} / \mathrm{v}) \mathrm{NaCl}$ and at $4-37^{\circ} \mathrm{C}$ on PYE agar. No growth occurs at $42^{\circ} \mathrm{C}$. On PYE agar, yellow, irregular, leathery, dry, wrinkled colonies form within $48 \mathrm{~h}$, with a diameter of approximately 1-5 mm. After 3-5 days, colonies can be up to $8 \mathrm{~mm}$ in diameter. The quinone system of strain $\mathrm{C} 36^{\mathrm{T}}$ consists of Q-9 $(96 \%)$ and Q-8 (4\%). Polyamine pattern consists of the major compounds putrescine and spermidine [ 98.8 and $18 \cdot 5 \mu \mathrm{mol}$ (g dry wt) ${ }^{-1}$, respectively] and minor amounts of spermine and diaminopropane $[0.7$ and $0.3 \mu \mathrm{mol}$ (g dry $\mathrm{wt})^{-1}$, respectively]. Predominant polar lipids are diphosphatidylglycerol, phosphatidylglycerol, phosphatidylethanolamine and phosphatidylcholine. Additionally, moderate amounts of an unidentified phospholipid and an unknown lipid are present, as well as small amounts of an unidentified aminophospholipid and an unknown lipid. Fatty acid composition of strain $\mathrm{C} 36^{\mathrm{T}}$ is as follows: $\mathrm{C}_{18: 1} \omega 7 c(49 \cdot 1 \%)$, $\mathrm{C}_{16: 0}(22 \cdot 6 \%)$, summed feature $3\left(\mathrm{C}_{16: 1} \omega 7 \mathrm{c}\right.$ and/or $2-\mathrm{OH}$ $\mathrm{C}_{15: 0}$ iso; $\left.16 \cdot 9 \%\right), \mathrm{C}_{12: 0}(4 \cdot 5 \%), 3-\mathrm{OH} \mathrm{C}_{12: 0}(3 \cdot 0 \%)$, $3-\mathrm{OH} \mathrm{C}_{10: 0}(2 \cdot 6 \%)$ and $2-\mathrm{OH} \mathrm{C}_{12: 0}(1 \cdot 8 \%)$. Other characteristics are listed in Table 1.

The type strain is $\mathrm{C}^{2} 6^{\mathrm{T}}\left(=\mathrm{LMG} 21977^{\mathrm{T}}=\mathrm{DSM} 15758^{\mathrm{T}}\right)$. Reference strains are C37 and C39. Strains $\mathrm{C} 36^{\mathrm{T}}$ and C37 were isolated from water under a dog's cage and C39 was isolated from a strip of metal under the treatment table in the Medical Clinic for Small Animals, University for Veterinary Medicine, Vienna, Austria.

\section{Acknowledgements}

We are grateful to G. Schroll for providing strains and to the people from the Medical Clinic for Small Animals and Ungulates, who gave us all the support that we needed.

\section{References}

Altenburger, P., Kämpfer, P., Makristathis, A., Lubitz, W. \& Busse, H.-J. (1996). Classification of bacteria isolated from a medieval wall painting. J Biotechnol 47, 39-52.

Auling, G., Busse, H.-J., Pilz, F., Webb, L., Kneifel, H. \& Claus, D. (1991). Rapid differentiation, by polyamine analysis, of Xanthomonas 
strains from phytopathogenic pseudomonads and other members of the class Proteobacteria interacting with plants. Int J Syst Bacteriol 41, 223-228.

Busse, H.-J. \& Auling, G. (1988). Polyamine pattern as a chemotaxonomic marker within the Proteobacteria. Syst Appl Microbiol 11, $1-8$.

Busse, H.-J., Bunka, S., Hensel, A. \& Lubitz, W. (1997). Discrimination of members of the family Pasteurellaceae based on polyamine patterns. Int J Syst Bacteriol 47, 698-708.

Busse, H.-J., Kämpfer, P. \& Denner, E. B. M. (1999). Chemotaxonomic characterisation of Sphingomonas. J Ind Microbiol Biotechnol 23, 242-251.

Felsenstein, F. (1995). PHYLIP (Phylogeny Inference Package) version 3.57c. Seattle: University of Washington.

Kämpfer, P., Steiof, M. \& Dott, W. (1991). Microbiological characterisation of a fuel-oil contaminated site including numerical identification of heterotrophic water and soil bacteria. Microb Ecol 21, 227-251.

Kämpfer, P., Denner, E. B. M., Meyer, S., Moore, E. R. B. \& Busse, H.-J. (1997). Classification of "Pseudomonas azotocolligans" Anderson 1955, 132, in the genus Sphingomonas as Sphingomonas trueperi sp. nov. Int J Syst Bacteriol 47, 577-583.

Kämpfer, P., Buczolits, S., Albrecht, A., Busse, H.-J. \& Stackebrandt, E. (2003). Towards a standardized format for the description of a novel species (of an established genus): Ochrobactrum gallinifaecis sp. nov. Int J Syst Evol Microbiol 53, 893-896.

Moore, E. R. B., Mau, M., Arnscheidt, A., Böttger, E. C., Hutson, R. A., Collins, M. D., Van De Peer, Y., De Wachter, R. \& Timmis, K. N. (1996). The determination and comparison of the $16 \mathrm{~S}$ rRNA gene sequences of species of the genus Pseudomonas (sensu stricto) and estimation of the natural intrageneric relationships. Syst Appl Microbiol 19, 478-492.
Oyaizu, H. \& Komagata, K. (1983). Grouping of Pseudomonas species on the basis of cellular fatty acid composition and the quinone system with special reference to the existence of 3-hydroxy fatty acids. J Gen Appl Microbiol 29, 17-40.

Page, R. D. M. (1996). TREeVIEW: an application to display phylogenetic trees on personal computers. Comput Appl Biosci 12, 357-358.

Pearson, W. R. \& Lipman, D. J. (1988). Improved tools for biological sequence comparison. Proc Natl Acad Sci U S A 85, 2444-2448.

Saitou, N. \& Nei, M. (1987). The neighbor-joining method: a new method for reconstructing phylogenetic trees. Mol Biol Evol 4, 406-425.

Thompson, J. D., Gibson, T. J., Plewniak, F., Jeanmougin, F. \& Higgins, D. G. (1997). The CLUSTAL_X windows interface: flexible strategies for multiple sequence alignment aided by quality analysis tools. Nucleic Acids Res 25, 4876-4882.

Tindall, B. J. (1990). A comparative study of the lipid composition of Halobacterium saccharovorum from various sources. Syst Appl Microbiol 13, 128-130.

van Beilen, J. B., Panke, S., Lucchini, S., Franchini, A. G., Röthlisberger, M. \& Witholt, B. (2001). Analysis of Pseudomonas putida alkane-degradation gene clusters and flanking insertion sequences: evolution and regulation of the alk genes. Microbiology 147, 1621-1630.

Wieser, M. \& Busse, H.-J. (2000). Rapid identification of Staphylococcus epidermidis. Int J Syst Evol Microbiol 50, 1087-1093.

Ziemke, F., Höfle, M. G., Lalucat, J. \& Rosselló-Mora, R. (1998). Reclassification of Shewanella putrefaciens Owen's genomic group II as Shewanella baltica sp. nov. Int J Syst Bacteriol 48, 179-186.

Zlamala, C., Schumann, P., Kämpfer, P., Rosselló-Mora, R., Lubitz, W. \& Busse, H.-J. (2002). Agrococcus baldri sp. nov., isolated from the air in the 'Virgilkapelle' in Vienna. Int J Syst Evol Microbiol 52, 1211-1216. 